\title{
Feto-maternal Haemorrhage in Therapeutic Abortion
}

\author{
J. C. VOIGT,* M.R.C.P.ED., F.R.C.S., M.R.C.o.G. ; R. P. BRITT,† M.B., CH.B., M.C.PATH.
}

Summary : The incidence of feto-maternal haemorrhage $\checkmark$ in induced abortion has been studied with the Kleihauer technique. All four methods of termination used were shown to result in such haemorrhages. The incidence below 12 weeks' gestation, however, was very small and there seems to be no reason for offering routine rhesus-immunoglobulin to these women. When it is essential to terminate a pregnancy of 12 weeks' size or more in a rhesus-negative woman immunoglobulin should be given.

\section{Introduction}

In 1960 Finn put forward the idea that it might be possible to prevent rhesus isoimmunization by giving the rhesusnegative mother an antibody against rhesus-positive fetal cells. Since then much interest has been focused on the passage of fetal cells into the maternal circulation. With the staining method introduced by Kleihauer, Braun, and Betke (1957) it was shown that appreciable transplacental haemorrhage could occur during the third stage of labour (Zipursky, Hull, White, and Israels, 1959 ; Finn et al., 1961). Krieger (1966), in a study on the appearance of antibodies in the maternal serum, produced evidence that transplacental bleeding could also occur during the antepartum phase. Zipursky, Pollock Chown, and Israels (1963) found that haemorrhage resulted also from operative procedures which damaged the placental site. In particular, with amniocentesis, not only was large transplacental haemorrhage demonstrable, but a sudden sharp rise in antibody titre followed where the fetus was rhesuspositive. Gellén, Kovács, Szontágh, and Boda (1965) showed that surgical termination of early pregnancy produced similar

* Senior Registrar in Obstetrics and Gynaecology.

† Consultant Haematologist.

Hillingdon Hospital, Uxbridge, Middlesex. leakage of fetal red cells into the maternal circulation. Matthews and Matthews (1969) confirmed this and also found that Kleihauer tests were positive in about $6 \%$ of spontaneous abortions.

We present here a study of the incidence of positive Kleihauer tests in therapeutic termination of pregnancy, with particular regard to the maturity of the pregnancy and the method of termination.

\section{Materials and Methods}

The cases were 212 unselected patients undergoing termination of pregnancy. Almost without exception the indications were psychiatric and the pregnancies were otherwise normal. They were classified into four groups according to the gynaecological procedure :

(1) Dilatation of the cervix and uterine curettage (53 cases).

(2) Suction vaginal termination with gentle curettage 88 cases). Commonly, the completeness of evacuation was then confirmed by gentle exploration of the uterus with the conventional curette. Where, in a few cases, the suction evacuation was incomplete, ovum forceps and sharp or blunt curettage were used and the case was classified in the dilatation and curettage group.

(3) Abdominal hysterotomy (37 cases). This was generally a classical caesarean section type of operation in miniature (often combined with sterilization).

(4) Injection of Utus paste (a soap paste containing not more than $2 \%$ iodine) (34 cases). This was generally done without anaesthesia and the amount was varied according to the manufacturer's recommendations. If the conscious patient experienced pain or vomiting or other disturbing symptoms injection was discontinued.

Careful note was made of the uterine size at operation, as estimated in weeks. Where this was at variance with the stated duration of amenorrhoea the estimated size was taken as more relevant.

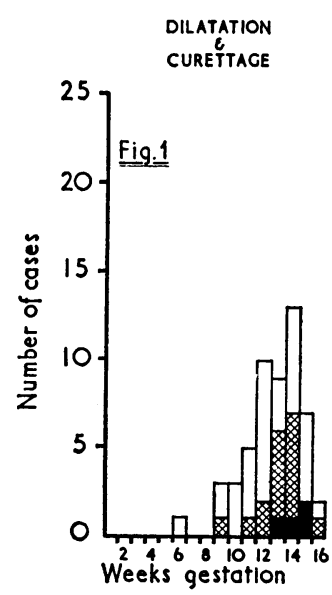

FIG. 1

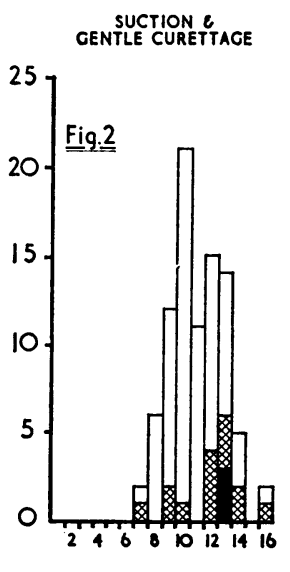

FIG. 2

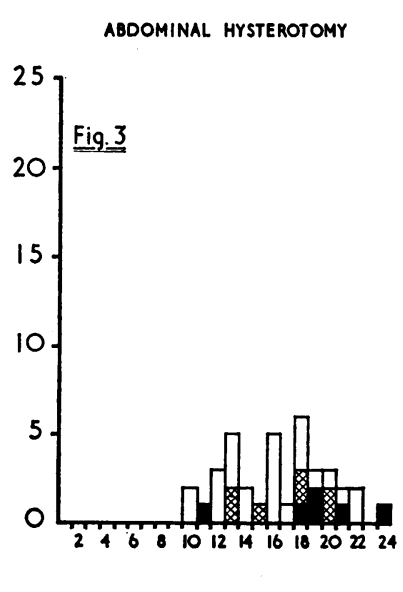

FIG. 3

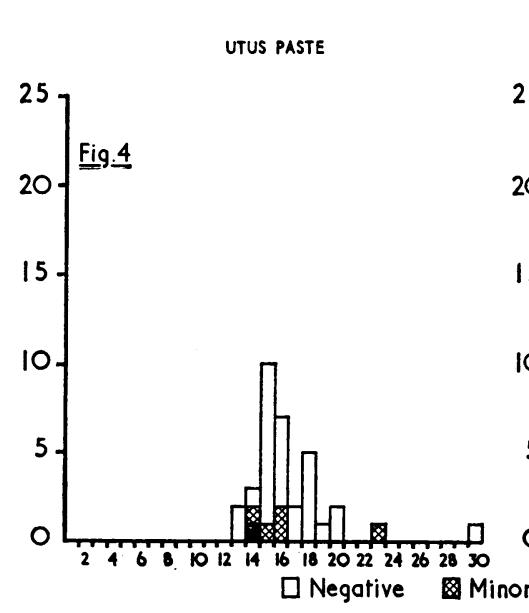

FIG. 4

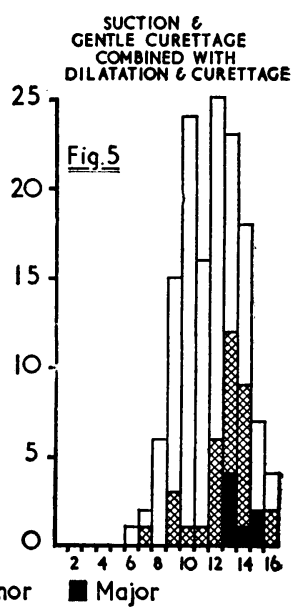

FIG. 5

Fig. 1.-Feto-maternal haemorrhages after dilatation and curettage. Fig. 2.- Feto-maternal haemorrhages after suction and gentle curettage. FIG. 3.-Feto-maternal haemorrhages after abdominal hysterotomy. FiG. 4.- Feto-maternal haemorrhages after Utus paste injection. FiG. 5.-
Chart showing feto-maternal haemorrhages for the group of dilatation and curettage combined with the group of suction with gentle curettage. 
Venous blood samples were collected within 12 hours of the gynaecological procedure. Blood films were stained by the Liverpool modification of the Kleihauer technique (Woodrow and Finn, 1966). Fetal cell counts were made in 50 selected uniform low-power fields on each of two slides. The fetal cell count was expressed as the average of the two counts. The results are classified as major or high risk haemorrhage when there were 5 or more per 50 low-power fields and minor or low risk when fewer than 5 per 50 low-power fields. A count of 5 cells per 50 low-power fields has been calculated to represent $0.25 \mathrm{ml}$. of fetal blood in the maternal circulation (Combined Study, 1966).

\section{Results}

In each of the four groups the results are expressed schematically (Figs. 1-4). In Fig. 5 the results of the dilatation and curettage group are combined with those of the suction vaginal termination group. In each figure the number of cases is charted for each week of pregnancy and major and minor haemorrhages are shown.

In the 212 cases there were $56(26.4 \%)$ feto-maternal haemorrhages, "major" haemorrhage occurring in $14(6.6 \%)$.

\section{Discussion}

In a series of 221 terminations of pregnancy Matthews and Matthews (1969) found transplacental haemorrhage in about $25 \%$, which was thought to be potentially immunizing in $3 \%$. The overall incidence of haemorrhage in the series of cases reported here $(26.4 \%)$ is in close agreement with these findings, but in our series there was a higher incidence of major bleeds $(6 \cdot 6 \%)$. This higher incidence is almost certainly related to the different criteria taken for a major haemorrhage ( 5 cells per 50 low-power fields in our study). It is possible that minor differences in incidence from one centre to another could result from variation in interpretation in the Kleihauer films of the so-called "intermediate" cells. Matthews and Matthews (1969) also suggested that suction vaginal termination might prove less likely to cause feto-maternal haemorrhage, but the technique was used in only a small number of their cases. When the preponderance of the use of suction technique in less advanced cases is taken into consideration (Fig. 2) and the use of dilatation and curettage in more advanced pregnancy (Fig. 1) our results show that the difference is not very great. In the 36 cases of suction termination at 12 weeks and over 13 haemorrhages occurred, three of which were 5 or more cells per 50 low-power fields; in the 41 with dilatation and curettage 18 haemorrhages were recorded, four with 5 or more cells per 50 low-power fields.
To our knowledge it has not hitherto been shown that simple injection of abortifacient paste into the chorio-decidual space can be responsible for feto-maternal haemorrhage. There is commonly a latent period of up to 36 hours after the injection of Utus paste before the abortion process begins. Our samples were collected before any such signs of onset of abortion. It could be postulated that injection of material into the chorio-decidual space in this way might result in some disruption of the feto-maternal barrier and at the same time provide a temporary positive-pressure gradient across open maternal venous channels. In our 34 cases treated in this way there were five minor and one major haemorrhages. Admittedly these numbers are small, and in view of the problems previously mentioned in relation to the Kleihauer staining technique further work is required to confirm these findings with Utus paste injection.

Our study provides the first detailed comparison of the incidence of feto-maternal haemorrhage in therapeutic abortion in relation to duration of pregnancy as judged by uterine size. One might expect that the more advanced the pregnancy the more fetal red cells would be available and the area of the "placental" barrier to be disrupted would be greater. Analysis of our figures shows that the duration of pregnancy is important. Out of 64 vaginal terminations carried out before 12 weeks only $6(9 \cdot 4 \%)$ showed feto-maternal haemorrhage, whereas $31(40.3 \%)$ cases out of 77 were positive from 12 weeks onwards (Fig. 5). Of even greater significance is the fact that no major transplacental haemorrhage occurred in either group before the 12th week of gestation, stressing the importance of early termination of pregnancy if the risk of rhesus sensitization is to be minimized.

We wish to thank Mr. J. Gray for technical assistance, the consultants concerned for permission to study patients under their care, and Mr. E. G. Jonas for his encouragement.

\section{REFERENCES}

Combined Study from Centres in England and Baltimore (1966). British Medical fournal, 2, 907.

Finn, R. (1960). Lancet, 1, 526

Finn, R., et al. (1961). British Medical fournal, 1, 1486.

Gellén, J., Kovács, Z., Szontágh, F. E., and Boda, D. (1965). British Medical fournal, 2, 1471

Kleihauer, E., Braun, H., and Betke, K. (1957). Klinische Wochenschrift, 35, 637.

Krieger, V. I. (1966). Fournal of Obstetrics and Gynaecology of the British Commonwealth, 73, 99.

Matthews, C. D., and Matthews, A E. B. (1969), Lancet, 1, 694.

Woodrow, J. C., and Finn, R. (1966). British fournal of Haematology, 12, 297.

Zipursky, A., Hull, A., White, F. D., and Israels, L. G. (1959). Lancet,

1, 451 . 2, 493 . 